\title{
The impact of spine disease, relative to cranial disease, on perception of health and care experience: an analysis of 1484 patients in a tertiary center
}

\author{
Panagiotis Kerezoudis, MD, ${ }^{1,2}$ Mohammed Ali Alvi, MBBS, ${ }^{1,2}$ Daniel S. Ubl, MPH, ${ }^{3}$ \\ Kristine T. Hanson, MPH, ${ }^{3}$ William E. Krauss, MD, ${ }^{2}$ Fredric B. Meyer, MD, ${ }^{2}$ Robert J. Spinner, MD, ${ }^{2}$ \\ Elizabeth B. Habermann, MPH, PhD, ${ }^{3}$ and Mohamad Bydon, MD ${ }^{1,2}$
}

\begin{abstract}
${ }^{1}$ Mayo Clinic Neuro-Informatics Laboratory; ${ }^{2}$ Department of Neurosurgery; and ${ }^{3}$ Surgical Outcomes Program, Robert D. and Patricia E. Kern Center for the Science of Health Care Delivery, Mayo Clinic, Rochester, Minnesota
\end{abstract}

\begin{abstract}
OBJECTIVE Patient-reported outcomes have been increasingly mandated by regulators and payers to evaluate hospital and physician performance. The purpose of this study is to delineate the differences in patient-reported experience of hospital care for cranial and spinal operations.

METHODS The authors selected all patients who underwent inpatient, elective cranial or spinal procedures and completed the Hospital Consumer Assessment of Healthcare Providers and Systems (HCAHPS) survey at a single, highvolume, tertiary care institution between October 2012 and September 2015. The association of the surgical procedure and diagnosis with various HCAHPS composite measures, calculated across 9 domains using standard top-box methodology, was investigated. Multivariable logistic regression models were fitted for outcomes that were significant with procedure type and diagnosis group on univariate analysis, adjusting for age, sex, case complexity, overall health rating, and education level.
\end{abstract}

RESULTS A total of 1484 patients met criteria and returned an HCAHPS survey. Overall, patients undergoing a cranial procedure gave top-box (most favorable) scores more often in pain management measure $(66.3 \%$ vs $59.6 \%, p=0.01$ ) compared with those undergoing spine surgery. Furthermore, despite better discharge scores $(93.1 \%$ vs $87.1 \%, p<$ $0.001)$, spinal patients were less likely to report excellent health $(7.4 \%$ vs $12.7 \%)$. Lastly, patients with a primary diagnosis of brain or spinal tumor compared with those with degenerative spinal disease and those with other neurosurgical diagnoses provided top-box scores more often regarding communication with doctors $(82.7 \%$ vs $76.4 \%$ vs $75.2 \%, p=0.04)$, pain management $(71.8 \%$ vs $60.9 \%$ vs $59.1 \%, p=0.002)$, and global rating ( $90.4 \%$ vs $84.0 \%$ vs $87.3 \%, p=0.02)$. On multivariable analysis, spinal patients had significantly lower odds of reporting top-box scores in pain management (OR $0.67,95 \% \mathrm{Cl} 0.52-0.85 ; p=0.001$ ), staff responsiveness (OR 0.68, 95\% Cl 0.53-0.87; $p=0.002$ ), and global rating (OR $0.59,95 \% \mathrm{Cl} 0.42-0.82 ; \mathrm{p}=0.002$ ), and significantly higher odds of top-box scoring in discharge information (OR 2.15, $95 \% \mathrm{Cl} 1.45-3.18 ; p<0.001)$ than cranial patients. Similarly, brain tumor cases were associated with significantly higher odds of top-box scoring in communication with doctors (OR 1.46, 95\% Cl 1.01-2.12; $p=0.04$ ), pain management (OR $1.81,95 \% \mathrm{Cl} 1.29-2.55 ; p<0.001)$, staff responsiveness (OR 1.88, 95\% Cl 1.33-2.66; $p<0.001)$, and global rating (OR $2.00,95 \% \mathrm{Cl} 1.26-3.17 ; \mathrm{p}=0.003)$ compared with degenerative spine cases.

CONCLUSIONS Significant differences in patient-reported experience with hospital care exist across different cranial and spine surgery patient populations. Overall, spinal patients, particularly those with degenerative spine disease, rated their health and their hospital experience lower relative to cranial patients. Identifying weaker areas of hospital performance in target populations can stimulate quality initiatives that aim to increase the overall hospital score.

https://thejns.org/doi/abs/10.3171/2017.7.JNS17991

KEY WORDS patient experience; spinal; cranial; HCAHPS; neurosurgery; pain management; patient communication

ABBREVIATIONS CMS = Centers for Medicare and Medicaid Services; HCAHPS = Hospital Consumer Assessment of Healthcare Providers and Systems; ICD-9 = International Classification of Diseases, Ninth Revision.

SUBMITTED April 19, 2017. ACCEPTED July 24, 2017.

INCLUDE WHEN CITING Published online January 26, 2018; DOI: 10.3171/2017.7.JNS17991. 
TABLE 1. HCAHPS composite measures and associated questions

\begin{tabular}{|c|c|}
\hline HCAHPS Question No. & Question \\
\hline \multicolumn{2}{|l|}{ Communication w/ nurses } \\
\hline 1 & During this hospital stay, how often did nurses treat you with courtesy and respect? \\
\hline 2 & During this hospital stay, how often did nurses listen carefully to you? \\
\hline 3 & During this hospital stay, how often did nurses explain things in a way you could understand? \\
\hline \multicolumn{2}{|l|}{ Communication w/ doctors } \\
\hline 5 & During this hospital stay, how often did doctors treat you with courtesy and respect? \\
\hline 6 & During this hospital stay, how often did doctors listen carefully to you? \\
\hline 7 & During this hospital stay, how often did doctors explain things in a way you could understand? \\
\hline \multicolumn{2}{|c|}{ Responsiveness of hospital staff } \\
\hline 4 & During this hospital stay, after you pressed the call button, how often did you get help as soon as you wanted it? \\
\hline 11 & How often did you get help in getting to the bathroom or in using a bedpan as soon as you wanted? \\
\hline \multicolumn{2}{|l|}{ Pain management } \\
\hline 13 & During this hospital stay, how often was your pain well controlled? \\
\hline 14 & During this hospital stay, how often did the hospital staff do everything they could to help you with your pain? \\
\hline \multicolumn{2}{|c|}{ Communication about medicines } \\
\hline 16 & Before giving you any new medicine, how often did hospital staff tell you what the medicine was for? \\
\hline 17 & $\begin{array}{l}\text { Before giving you any new medicine, how often did hospital staff describe possible side effects in a way you could } \\
\text { understand? }\end{array}$ \\
\hline \multicolumn{2}{|l|}{ Discharge information } \\
\hline 19 & $\begin{array}{l}\text { During this hospital stay, did doctors, nurses or other hospital staff talk with you about whether you would have } \\
\text { the help you needed when you left the hospital? }\end{array}$ \\
\hline 20 & $\begin{array}{l}\text { During this hospital stay, did you get information in writing about what symptoms or health problems to look out } \\
\text { for after you left the hospital? }\end{array}$ \\
\hline \multicolumn{2}{|l|}{ Care transition } \\
\hline 23 & $\begin{array}{l}\text { During this hospital stay, staff took my preferences and those of my family or caregiver into account in deciding } \\
\text { what my health care needs would be when I left. }\end{array}$ \\
\hline 24 & When I left the hospital, I had a good understanding of the things I was responsible for in managing my health. \\
\hline 25 & When I left the hospital, I clearly understood the purpose for taking each of my medications. \\
\hline \multicolumn{2}{|l|}{ Hospital environment } \\
\hline 8 & During this hospital stay, how often were your room and bathroom kept clean? \\
\hline 9 & During this hospital stay, how often was the area around your room quiet at night? \\
\hline \multicolumn{2}{|l|}{ Global rating } \\
\hline 21 & $\begin{array}{l}\text { Using any number from } 0 \text { to } 10 \text {, where } 0 \text { is the worst hospital possible and } 10 \text { is the best hospital possible, what } \\
\text { number would you use to rate this hospital during your stay? }\end{array}$ \\
\hline 22 & Would you recommend this hospital to your friends and family? \\
\hline
\end{tabular}

The questions appear out of order based on the complexity measures. Patients were administered the HCAHPS survey as specified (at www.hcahpsonline.org). Questions 1-22 are part of the HCAHPS survey and are works of the US government. These HCAHPS questions are in the public domain and therefore are not subject to US copyright laws. The 3 care transition measure questions (Questions 23-25) are copyright of Eric A. Coleman, MD, MPH, all rights reserved, published with permission.

$\mathrm{V}$ ALUE-BASED purchasing is the current form of payfor-performance model employed by the Centers for Medicare and Medicaid Services (CMS) (https://www.cms.gov/Outreach-and-Education/Medi care-Learning-Network-MLN/MLNProducts/downloads/ Hospital_VBPurchasing_Fact_Sheet_ICN907664.pdf). It was executed as part of the Affordable Care Act in 2010. According to this model, incentives and rewards are granted to hospitals and providers for adhering to quality standards, thus setting up behavior modifications through motivation for higher pay. ${ }^{25}$ These models were initiated to curb skyrocketing gross health care expenditures, as ex- emplified by total health care spending of $\$ 3.0$ trillion in the United States in 2013 (https://www.cms.gov/researchstatistics-data-and-systems/statistics-trends-and-reports/ nationalhealthexpenddata/).

As part of the program, patient experience with hospital care has become an integral part of calculating valuebased incentive payments, accounting for 30\% of hospital Medicare reimbursements between fiscal years 2013 and $2015 .^{8,9}$ The standardized measure for quantifying inpatient experience is the Hospital Consumer Assessment of Healthcare Providers and Systems (HCAHPS) survey, which constitutes a CMS-approved set of measures 
TABLE 2. Summary of demographic characteristics of studied patient population

\begin{tabular}{|c|c|}
\hline Variable & No. of Patients (\%) \\
\hline \multicolumn{2}{|l|}{ Age group in yrs } \\
\hline $18-24$ & $34(2.29)$ \\
\hline $25-34$ & $39(2.63)$ \\
\hline $35-44$ & $92(6.2)$ \\
\hline $45-54$ & $207(13.95)$ \\
\hline $55-64$ & $384(25.88)$ \\
\hline $65-74$ & $477(32.14)$ \\
\hline $75-84$ & $229(15.43)$ \\
\hline$\geq 85$ & $22(1.48)$ \\
\hline \multicolumn{2}{|l|}{ Sex } \\
\hline Female & $692(46.63)$ \\
\hline Male & $792(53.37)$ \\
\hline \multicolumn{2}{|l|}{ Race } \\
\hline White & $1224(82.48)$ \\
\hline Black or African American & $11(0.74)$ \\
\hline Asian & $1(0.07)$ \\
\hline Native Hawaiian or other Pacific Islander & $10(0.67)$ \\
\hline American Indian or Alaska Native & $5(0.34)$ \\
\hline Other & $233(15.7)$ \\
\hline \multicolumn{2}{|l|}{ Highest grade completed } \\
\hline$\leq 8$ th grade & $8(0.55)$ \\
\hline Some high school, but did not graduate & $28(1.91)$ \\
\hline High school graduate or GED & $365(24.95)$ \\
\hline Some college or 2-yr degree & $480(32.81)$ \\
\hline 4-yr college graduate & $293(20.03)$ \\
\hline$>4$-yr college degree & $289(19.75)$ \\
\hline \multicolumn{2}{|l|}{ Main language } \\
\hline English & $1443(99.18)$ \\
\hline Spanish & $4(0.27)$ \\
\hline Chinese & $1(0.07)$ \\
\hline Portuguese & $5(0.34)$ \\
\hline Other & $2(0.14)$ \\
\hline
\end{tabular}

grouped into specific quality domains..$^{12}$ It was originally developed by the CMS in alliance with the Agency for Healthcare Research and Quality (AHRQ) in 2002.1 The first implementation of the survey took place in October 2006, and the results were first publicly reported in March 2006. In addition to hospital reimbursement, HCAHPS has also been linked to patient experience as a marker of clinical quality and patient-centered approaches. Several efforts to improve overall patient experience with hospital care have been reported before, such as using handoff procedures in front of patients, ${ }^{6}$ providing patients with essential information up front, ${ }^{18}$ and implementing face cards at patients' bedsides to improve patients' knowledge of the names and roles of physicians. ${ }^{26}$

Several studies have explored HCAHPS data to identify the key factors leading to poor patient experience with hospital care across multiple surgical specialties, including general, orthopedic, and transplant surgery. $1,3,10,13,15,19,21$,
${ }^{23,27}$ However, there is a paucity of relevant literature in the realm of cranial and spinal surgery. Herein, we analyzed our institutional HCAHPS data to identify differences in reported experience with hospital care among patient groups undergoing common elective cranial and spinal procedures. We also evaluated and identified components of patient experience using key driver analysis to provide objective evidence of need for improvement in these areas.

\section{Methods}

\section{Data Source and Patient Cohort}

After obtaining institutional review board approval, we queried an administrative billing database for patients who underwent elective cranial and spinal surgery and were discharged from a single institution (October 1,2012, to September 30,2015$)$. Only patients who provided consent to access their medical records were included in the study. Medical information on demographic data, diagnoses, and operative characteristics was abstracted from our institutional electronic database. Patients were included if they had a Current Procedural Terminology (CPT) code indicative of a cranial or a spinal operation documented with their index hospitalization (Supplemental Table 1). In addition, patients were categorized into diagnosis groups according to the primary admission International Classification of Diseases, Ninth Revision (ICD-9) code, which comprised the following (Supplemental Table 2): 1) benign or malignant brain tumor, 2) benign or malignant spinal tumor, 3) degenerative spine disease, and 4) other diagnoses, including intracranial aneurysm, normal pressure hydrocephalus, and movement disorders. Patients with more than one diagnosis were assigned hierarchically; for example, patients with both brain tumor and degenerative spine disease were assigned to the CNS tumor group. Details pertaining to CPT and ICD-9 codes used to identify the patient cohort are provided in Supplemental Tables 1 and 2. Nonelective cases $(n=611)$ and patients who refused authorization to access their records $(n=282)$ were also excluded from this study. Lastly, patients were excluded from the analysis if they were not sampled to fill out the survey or if they were selected but did not complete it $(n=4826,76.5 \%)$.

\section{HCAHPS Analysis}

HCAHPS is administered in a random fashion to adult inpatients from 48 hours to 6 weeks after hospital discharge and is available in English, Chinese, Spanish, Russian, and Vietnamese language versions. Patients may answer the questions in 4 different modes: telephone, mail, mail with telephone follow-up, or interactive voice recognition. In our study, all questionnaires were administered by mail. The survey consists of 32 items that measure a patient's impression of the hospital experience. The core of the survey consists of 21 questions that inquire about patient experience, 4 demographic questions, 5 screening questions, and 2 questions related to mental and overall health (Table 1). ${ }^{11}$

We used top-box methodology to combine the results into 7 CMS-designed composite measures: communication with doctors, communication with nurses, responsive- 
TABLE 3. Demographic characteristics of cranial versus spinal procedures

\begin{tabular}{|c|c|c|c|c|}
\hline \multirow[b]{2}{*}{ Variable } & \multicolumn{3}{|c|}{ Procedure Type } & \multirow[b]{2}{*}{$p$ Value } \\
\hline & All $(n=1481)$ & Cranial $(n=675)$ & Spinal $(n=806)$ & \\
\hline Age group in yrs & & & & $<0.001$ \\
\hline $18-24$ & $33(2.2)$ & $27(4.0)$ & $6(0.7)$ & \\
\hline $25-34$ & $39(2.6)$ & $24(3.6)$ & $15(1.9)$ & \\
\hline $35-44$ & $92(6.2)$ & $63(9.3)$ & $29(3.6)$ & \\
\hline $45-54$ & $206(13.9)$ & $111(16.4)$ & $95(11.8)$ & \\
\hline $55-64$ & $384(25.9)$ & $167(24.7)$ & $217(26.9)$ & \\
\hline $65-74$ & $476(32.1)$ & $196(29.0)$ & $280(34.7)$ & \\
\hline $75-84$ & $229(15.5)$ & $81(12.0)$ & $148(18.4)$ & \\
\hline$\geq 85$ & $22(1.5)$ & $6(0.9)$ & $16(2.0)$ & \\
\hline Sex & & & & $<0.001$ \\
\hline Female & $690(46.6)$ & $375(55.6)$ & $315(39.1)$ & \\
\hline Male & $791(53.4)$ & $300(44.4)$ & $491(60.9)$ & \\
\hline Race & & & & 0.18 \\
\hline White & $1221(82.4)$ & $555(82.2)$ & $666(82.6)$ & \\
\hline Black or African American & $11(0.7)$ & $2(0.3)$ & $9(1.1)$ & \\
\hline Asian & $1(0.1)$ & $1(0.1)$ & $0(0.0)$ & \\
\hline Native Hawaiian or other Pacific Islander & $10(0.7)$ & $3(0.4)$ & $7(0.9)$ & \\
\hline American Indian or Alaska Native & $5(0.3)$ & $1(0.1)$ & $4(0.5)$ & \\
\hline Other & $233(15.7)$ & $113(16.7)$ & $120(14.9)$ & \\
\hline Highest grade completed & & & & 0.068 \\
\hline High school graduate or less & $401(27.4)$ & $184(27.6)$ & $217(27.3)$ & \\
\hline Some college or 2-yr degree & $479(32.8)$ & $221(33.1)$ & $258(32.5)$ & \\
\hline 4-yr college graduate & $293(20.1)$ & $148(22.2)$ & $145(18.3)$ & \\
\hline$>4$-yr college degree & $288(19.7)$ & $114(17.1)$ & $174(21.9)$ & \\
\hline Rate overall health & & & & 0.001 \\
\hline Excellent & $143(9.8)$ & $84(12.7)$ & $59(7.4)$ & \\
\hline Very good & $532(36.5)$ & $243(36.7)$ & $289(36.4)$ & \\
\hline Good & $573(39.4)$ & $233(35.2)$ & $340(42.8)$ & \\
\hline Fair & $183(12.6)$ & $87(13.1)$ & $96(12.1)$ & \\
\hline Poor & $25(1.7)$ & $15(2.3)$ & $10(1.3)$ & \\
\hline Language & & & & 0.37 \\
\hline English & 1440 (99.2) & 652 (98.9) & $788(99.4)$ & \\
\hline Other & $12(0.8)$ & 7 (1.1) & $5(0.6)$ & \\
\hline
\end{tabular}

Non-p values are presented as the number of patients (column \%). Boldface type indicates statistical significance.

ness of hospital staff, communication about medicines, pain management, discharge information, and care transition. ${ }^{28}$ We also combined the 2 single-item hospital environment measures (quietness and environmental cleanliness) as well as the 2 global rating measures (hospital rating and recommendation) into composite measures. ${ }^{28}$ The top-box score is considered the most positive response to HCAHPS survey items and is defined as an "Always" response for each of the questions included in the 5 HCAHPS composites, "Yes" for each of the questions included in Discharge Information, "Strongly Agree" for each of the questions included in Care Transition, "9" or "10" for Overall Hospital Rating, and "Definitely Yes" for Recommend the Hospital. It is a methodology supported by CMS and is widely used for analyzing HCAHPS results. ${ }^{16,24}$ We then dichotomized scores for each composite measure as "high" (all top-box responses) versus "low" (at least one non-top-box response) for each composite measure. Lastly, using a previously published CMS methodology, we calculated the HCAHPS summary star score (http://www.hcahpsonline.org/en/hcahps-star-ratings/), which combines the composite measures recalculated on a continuous scale into a single summary measure ranging from 0 to 100. More information on HCAHPS can be found at www.hcahpsonline.org (Centers for Medicare \& Medicaid Services, Baltimore, MD. Accessed January 2, 2018).

\section{Statistical Analysis}

Descriptive statistics, including proportions and frequencies, were used to describe patient demographic in- 
TABLE 4. Comparison of composite measure scores between cranial and spinal procedure cohorts

\begin{tabular}{lccc}
\hline \multirow{2}{*}{ Composite Measure Score* } & \multicolumn{2}{c}{ Procedure } & \\
\cline { 2 - 3 } \multicolumn{1}{c}{ Communication w/ nurses } & $479(71.3)$ & $560(69.7)$ & 0.5 \\
\hline Communication w/ doctors & $529(78.8)$ & $609(76.1)$ & 0.22 \\
\hline Responsiveness of hospital staff & $446(72.3)$ & $504(66.1)$ & 0.014 \\
\hline Pain management & $385(66.3)$ & $463(59.6)$ & 0.012 \\
\hline Communication about medicines & $249(54.0)$ & $286(52.8)$ & 0.69 \\
\hline Discharge information & $535(87.1)$ & $678(93.1)$ & $<0.001$ \\
\hline Care transition & $366(55.2)$ & $435(55.0)$ & 0.94 \\
\hline Environment & $392(58.2)$ & $476(59.4)$ & 0.67 \\
\hline Global rating & $590(88.7)$ & $667(84.2)$ & 0.013 \\
\hline
\end{tabular}

Non-p values are presented as the number of patients (column \%). Boldface type indicates statistical significance.

* Top-boxing category.

formation. Clinical characteristics and HCAHPS composite measures were compared between spinal and cranial patients and across diagnosis groups using Wilcoxon ranksum tests for continuous variables and chi-square tests for categorical variables. Patients who underwent both spinal and cranial procedures were excluded from procedurespecific analysis. Significance was set at $p<0.05$. We also conducted multivariable logistic regression to investigate the effect of procedure and diagnosis on composite measure top-box scores after adjusting for age, sex, case complexity using Medicare-severity diagnosis-related groups, overall health rating, and education level. Lastly, we performed subgroup analysis of patients who underwent surgery performed by practitioners who perform both cranial and spinal procedures, to explore whether our observed findings simply reflect differences in interpersonal skills and practice patterns due to surgeon specialization.

Finally, we conducted key driver analysis to assess which of the 7 composite measures (communication with doctors, communication with nurses, responsiveness of hospital staff, communication about medicines, pain management, discharge information, and care transition) were important drivers of the global hospital composite measure. ${ }^{28}$ For each composite measure, we plotted the Spearman correlation coefficient of the continuous measure with the continuous global hospital rating against the average of the measure's score. ${ }^{28}$ Key driver analysis was completed for patients within each procedure group (spinal or cranial) and within each diagnosis group (degenerative spine disease, intracranial tumor, or other diagnoses). Statistical analysis was performed using SAS version 9.3 (SAS Institute Inc.). ${ }^{28}$

\section{Results}

We identified a total of 6310 patients who underwent an elective cranial or a spinal operation at our institution between October 1, 2012, and September 30, 2015, of whom 23.5\% ( $\mathrm{n}=1484)$ had a completed HCAHPS survey. The demographic information of our patient cohort is summarized in Table 2. The majority of patients were $65-74$ years old $(32.1 \%, \mathrm{n}=477)$, followed by $55-64$ years $(25.9 \%, \mathrm{n}=384)$ and $75-84$ years $(15.4 \%, \mathrm{n}=229)$. Males accounted for $53.4 \%$ of the studied cohort. Almost all patients (99.2\%) were English-language speaking. When we compared demographic characteristics between respondents and nonrespondents (Supplemental Table 3), we found that patients who did not fill out a survey were more likely to have undergone a cranial procedure $(51.2 \%$ vs $45.6 \%, \mathrm{p}<0.001$ ) and have a primary tumor diagnosis $(24.8 \%$ vs $20.7 \%, \mathrm{p}<0.001)$ and were more likely to have stayed 1 extra day in the hospital (median 3 days vs 2 days, $\mathrm{p}<0.001)$.

\section{Cranial Versus Spinal Procedures}

Our cohort consisted of $54.3 \%$ spinal patients $(n=$ 806), while cranial procedures represented $45.5 \%$ of the cohort $(n=675)$. Both spinal and cranial procedures were performed in 3 cases $(0.2 \%)$ and are excluded from procedure-specific analysis. Within both cohorts, the most common age group was 65-74 years $(29.0 \%, \mathrm{n}=196$ for cranial; $34.7 \%, \mathrm{n}=280$ for spinal). Sex distribution differed significantly across the 2 groups; less than half of the cranial cohort was male (44.4\%), while the majority of the spinal cohort was male $(60.9 \%)(\mathrm{p}<0.001)$. We also found that cranial patients were more inclined toward rating their health as "excellent" compared with spinal patients (84/675 patients [12.7\%] vs 59/806 [7.4\%]). We did not find any significant difference in racial diversity or education status between the 2 cohorts (both $\mathrm{p}>0.05$ ). This information, along with other details, is summarized in Table 3.

Within spinal cases, the majority of patients $(83.5 \%)$ underwent fusion $(\mathrm{n}=391)$ or laminectomy $(\mathrm{n}=282)$; there were 73 discectomy cases (9.1\%), 55 tumor cases (6.8\%), and 5 artificial disc replacements $(0.6 \%)$. Within cranial cases, the most frequent procedure reported was craniectomy for tumor/cyst or brain tumor $(\mathrm{n}=256$ [37.9\%], supratentorial $\mathrm{n}=197$ [29.2\%], and infratentorial $\mathrm{n}=59$ [8.7\%]), while $13.2 \%$ underwent functional procedures or deep brain stimulation (DBS) $(n=89) ; 11.4 \%$ were painrelated procedures (including microvascular decompression of the trigeminal nerve and rhizotomy) $(\mathrm{n}=77)$, and $7.1 \%$ had endovascular procedures $(n=48)$. Other cases $(30.4 \%, \mathrm{n}=205)$ included posttraumatic hydrocephalus (n $=57)$, vascular $(n=41)$, biopsy $(n=37)$, skull base $(n=$ $30)$, epilepsy $(n=19)$, Chiari malformation $(n=9)$, cranioplasty $(n=8)$, and infection $(n=4)$. We found that patients undergoing a cranial procedure were less likely to have a high discharge information score $(87.1 \%$ vs $93.1 \%$, p < 0.001 ), but were more likely to have a high score in the domain of pain management $(66.3 \%$ vs $59.6 \%, \mathrm{p}=0.01)$ and hospital staff responsiveness $(72.3 \%$ vs $66.1 \%, p=0.01)$ and more likely to report a high global rating $(88.7 \%$ vs $84.2 \%, \mathrm{p}=0.01)$ compared with those receiving a spinal operation (Table 4).

\section{CNS Tumor Versus Degenerative Spine Disease Versus Other Diagnoses}

One-fifth of cases $(20.7 \%, \mathrm{n}=307)$ were brain and spinal tumor cases (primary and metastasis), $49.2 \%$ were degenerative spine cases $(n=730)$, and $30.1 \%$ had other 
TABLE 5. Demographic characteristics of tumors, degenerative spine disease, and other neurosurgical procedures

\begin{tabular}{|c|c|c|c|c|}
\hline Variable & Brain \& Spinal Tumors $(n=307)^{*}$ & Degenerative Spine Disease $(n=730)$ & Other $(n=447) \dagger$ & $\mathrm{p}$ Value \\
\hline Age group in yrs & & & & $<0.001$ \\
\hline $18-24$ & $12(3.9)$ & $2(0.3)$ & $20(4.5)$ & \\
\hline $25-34$ & $13(4.2)$ & $13(1.8)$ & $13(2.9)$ & \\
\hline $35-44$ & $29(9.4)$ & $25(3.4)$ & $38(8.5)$ & \\
\hline $45-54$ & $55(17.9)$ & $86(11.8)$ & $66(14.8)$ & \\
\hline $55-64$ & $75(24.4)$ & $195(26.7)$ & $114(25.5)$ & \\
\hline $65-74$ & $80(26.1)$ & $256(35.1)$ & $141(31.5)$ & \\
\hline $75-84$ & $38(12.4)$ & $139(19.0)$ & $52(11.6)$ & \\
\hline$\geq 85$ & $5(1.6)$ & $14(1.9)$ & $3(0.7)$ & \\
\hline Sex & & & & $<0.001$ \\
\hline Female & $163(53.1)$ & $280(38.4)$ & $249(55.7)$ & \\
\hline Male & $144(46.9)$ & $450(61.6)$ & $198(44.3)$ & \\
\hline Race & & & & 0.06 \\
\hline White & $242(78.8)$ & $611(83.7)$ & $371(83.0)$ & \\
\hline Black or African American & $0(0.0)$ & $8(1.1)$ & $3(0.7)$ & \\
\hline Asian & $1(0.3)$ & $0(0.0)$ & $0(0.0)$ & \\
\hline Native Hawaiian or other Pacific Islander & $1(0.3)$ & $3(0.4)$ & $6(1.3)$ & \\
\hline American Indian or Alaska Native & $1(0.3)$ & $3(0.4)$ & $1(0.2)$ & \\
\hline Other & $62(20.2)$ & $105(14.4)$ & $66(14.8)$ & \\
\hline Highest grade completed & & & & 0.16 \\
\hline High school graduate or less & $80(26.4)$ & $201(28.0)$ & $120(27.2)$ & \\
\hline Some college or 2-yr degree & $105(34.7)$ & $233(32.4)$ & $142(32.2)$ & \\
\hline 4-yr college graduate & $65(21.5)$ & $126(17.5)$ & $102(23.1)$ & \\
\hline$>4$-yr college degree & $53(17.5)$ & $159(22.1)$ & $77(17.5)$ & \\
\hline Rate overall health & & & & 0.04 \\
\hline Excellent & $43(14.2)$ & $56(7.8)$ & $45(10.3)$ & \\
\hline Very good & $116(38.4)$ & $266(37.0)$ & $152(34.7)$ & \\
\hline Good & $100(33.1)$ & $299(41.6)$ & $174(39.7)$ & \\
\hline Fair & $39(12.9)$ & $88(12.2)$ & $56(12.8)$ & \\
\hline Poor & 4 (1.3) & $10(1.4)$ & $11(2.5)$ & \\
\hline Language & & & & 0.13 \\
\hline English & $294(98.3)$ & 716 (99.6) & 433 (99.1) & \\
\hline Other & $5(1.7)$ & $3(0.4)$ & $4(0.9)$ & \\
\hline
\end{tabular}

Non-p values are presented as the number of patients (column \%). Boldface type indicates statistical significance.

* Primary and metastasis.

$\dagger$ Aneurysms, hydrocephalus, and functional disorders.

TABLE 6. Comparison of composite measure scores between patients with a tumor diagnosis, degenerative spine disease, and other diagnoses

\begin{tabular}{|c|c|c|c|c|}
\hline Composite Measure Score & Brain \& Spinal Tumors $(n=307)^{*}$ & Degenerative Spine Disease $(n=730)$ & Other $(n=447) \dagger$ & $\mathrm{p}$ Value \\
\hline Communication w/ nurses & $229(74.8)$ & $507(69.6)$ & $304(68.3)$ & 0.13 \\
\hline Communication w/ doctors & $253(82.7)$ & $553(76.4)$ & $334(75.2)$ & 0.039 \\
\hline Responsiveness of hospital staff & $211(75.9)$ & $458(66.3)$ & $282(68.3)$ & 0.013 \\
\hline Pain management & $186(71.8)$ & $428(60.9)$ & $236(59.1)$ & 0.002 \\
\hline Communication about medicines & $120(53.6)$ & $257(52.0)$ & $158(55.1)$ & 0.71 \\
\hline Discharge information & $246(91.8)$ & $615(92.9)$ & $353(85.3)$ & $<0.001$ \\
\hline Care transition & $182(60.1)$ & $394(55.0)$ & $227(51.8)$ & 0.085 \\
\hline Environment & $180(58.8)$ & $431(59.4)$ & $259(58.1)$ & 0.91 \\
\hline Global rating & $274(90.4)$ & $602(84.0)$ & $384(87.3)$ & 0.018 \\
\hline
\end{tabular}

Non-p values are presented as the number of patients (column \%). Boldface type indicates statistical significance.

* Primary and metastasis.

† Aneurysms, hydrocephalus, and movement disorders. 
indications, including aneurysms, hydrocephalus, and functional neurosurgery diagnoses $(n=447$; Table 5$)$. We found no significant difference in age across the various diagnosis groups. The majority of degenerative spine cases were in male patients (61.6\%), while $46.9 \%$ and $44.3 \%$ of tumor cases and cases with other diagnoses were in male patients, respectively $(\mathrm{p}<0.001)$.

Patients with brain or spinal tumor were more likely to report a high score than patients with degenerative spine or other diagnoses for communication with doctors $(82.7 \%$ vs $76.4 \%$ vs $75.2 \%, p=0.04)$, responsiveness of hospital staff (75.9\% vs $66.3 \%$ vs $68.3 \%, p=0.01)$, and pain management $(71.8 \%$ vs $60.9 \%$ vs $59.1 \%, p=0.002)$ (Table 6$)$. For discharge information, patients with degenerative spine diagnosis were more likely to report a high score than those in the tumor patient group and other diagnosis group (92.9\% vs $91.8 \%$ vs $85.3 \%, \mathrm{p}<0.001)$. Overall, the global score was most likely to be high in patients in the brain or spinal tumor diagnosis groups compared with the degenerative diagnosis and other diagnosis groups $(90.4 \%$ vs $84.0 \%$ vs $87.3 \%, \mathrm{p}=0.02$ ). We did not detect any significant differences between diagnosis groups in communication with nurses, communication about medicines, care transition, and environment (all $\mathrm{p}>0.05$ ).

\section{Multivariable Analysis}

The results of the multivariable analysis are presented in Table 7. Spinal patients had significantly lower odds of reporting top-box scores in pain management (OR 0.67, 95\% CI 0.52-0.85; $\mathrm{p}=0.001)$, staff responsiveness (OR $0.68,95 \%$ CI $0.53-0.87 ; \mathrm{p}=0.002$ ), and global rating (OR $0.59,95 \%$ CI $0.42-0.82 ; \mathrm{p}=0.002$ ), and significantly higher odds of top-box scoring in discharge information (OR $2.15,95 \%$ CI $1.45-3.18 ; \mathrm{p}<0.001)$ than cranial patients. Similarly, brain tumor cases were associated with significantly higher odds of top-box scoring in communication with doctors (OR 1.46, 95\% CI 1.01-2.12; $\mathrm{p}=0.044$ ), pain management (OR 1.81, 95\% CI 1.29-2.55; $\mathrm{p}<0.001$ ), staff responsiveness (OR 1.88, 95\% CI 1.33-2.66; $\mathrm{p}<0.001$ ), and global rating (OR 2.00, 95\% CI 1.26-3.17; $\mathrm{p}=0.003$ ) compared with degenerative spine cases.

\section{Subgroup Analysis}

When we compared patients who were treated by a neurosurgeon who performs both cranial and spinal procedures, there was no significant difference with regard to communication with the doctors (OR $0.75,95 \%$ CI $0.46-$ 1.23 ; $p=0.26$ ), pain management (OR $0.91,95 \%$ CI $0.56-$ 1.46; $\mathrm{p}=0.68)$, discharge information (OR $0.98,95 \% \mathrm{CI}$ $0.51-1.88 ; p=0.94$ ), staff responsiveness (OR $0.90,95 \%$ CI $0.55-1.45 ; \mathrm{p}=0.65$ ), and global rating (OR $0.92,95 \%$ CI $0.46-1.85 ; \mathrm{p}=0.82$ ) between spinal and cranial patients (Supplemental Table 4).

\section{Key Driver Analysis}

Results of the key driver analyses are presented in Figs. 1 and 2. Within spinal procedures, the key drivers were found to be communication about medicines, care transition, and hospital environment. These factors had lower than average experience scores while having higher 

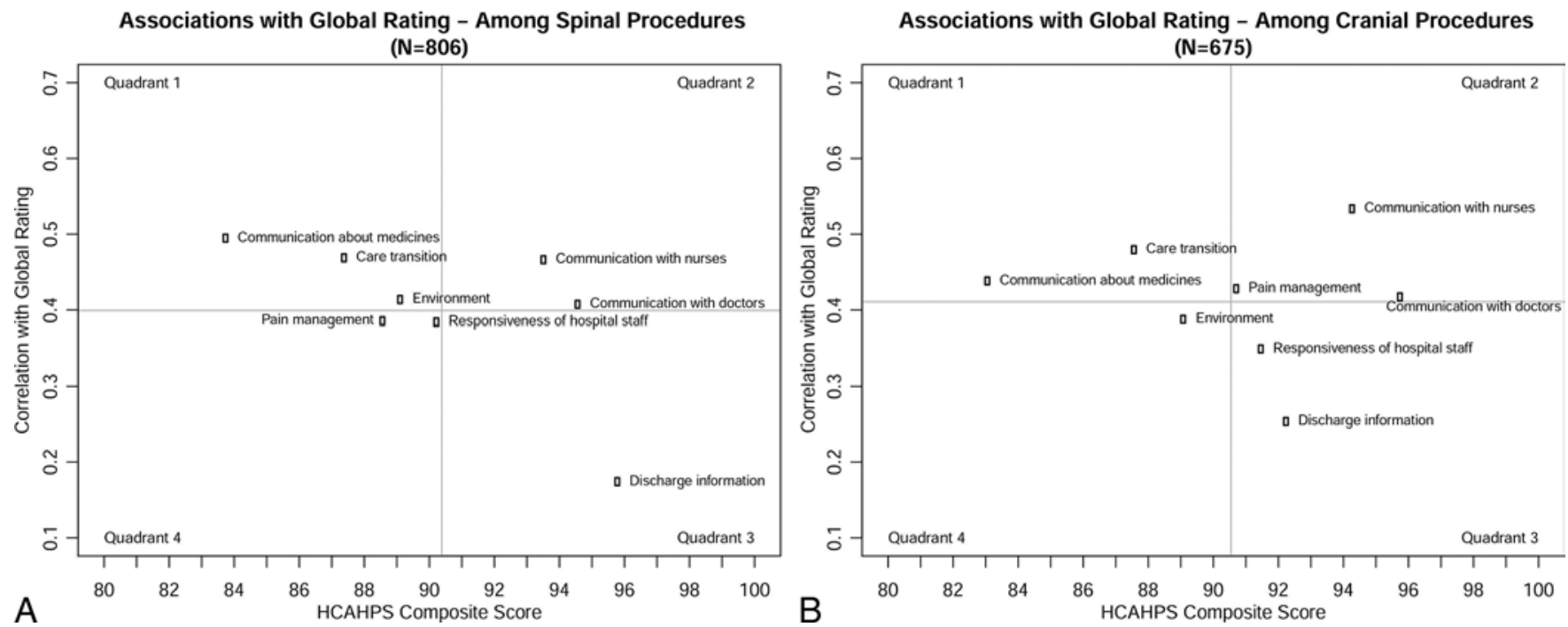

FIG. 1. Key driver analysis demonstrating the association between individual composite measures and global rating. The items falling into the first quadrant should be a first priority. These items have lower than average satisfaction levels while having higher than average correlation with the survey question listed on the $y$-axis. Items falling in quadrant 1 (top priority) for spinal patients $(A, n=806)$ are communication about medicines, care transition, and hospital environment; and for cranial patients $(B, n=675)$, communication about medicines and care transition.

than average correlation with the global HCAHPS rating. Among cranial patients, the key drivers were found to be communications about medicines and care transition. Within patients with brain or spinal tumor, care transition was found to be the only key driver of patient experience. For patients with degenerative spine disease, the key drivers were found to be communication about medicine, care transition, and environment. Lastly, for patients with other diagnoses, the key drivers were found to be communication about medicines, pain management, care transition, and environment.

\section{Discussion}

HCAHPS data not only are used for financial payment incentives but also allow physicians and administrators to gain key insights into the experiences of patients in the hospital and how they are affected by the various aspects of care. In the present study of nearly 1500 patients undergoing an elective cranial or spinal procedure in a single, tertiary academic center, substantial differences in the perceived experience of care were found across patient groups. These differences persisted even after adjusting for confounding variables, including age, sex, case complexity, overall health rating, and education level. Moreover, although most of these patients had high experience scores, we identified targets for improvement, including care transition and communication about medicines.

The comparison of tumors with degenerative spine disease and other neurosurgical diagnoses was performed on the rationale that patients with cancer are generally more grateful and satisfied with their hospital care than patients with noncancer diagnoses. Interestingly, pain management and various aspects of provider team-patient communication, i.e., communication with doctors and hospital staff responsiveness, were found to be significantly different be- tween these groups. In a previously reported study at our institution, Thiels and colleagues looked at patients undergoing colorectal surgery and found that younger patients and those with a diagnosis of inflammatory bowel disease or other noncancer diagnosis reported lower perceived quality of pain management. ${ }^{27}$ Notably, in that study the star score analysis revealed that patients with inflammatory bowel disease had the highest likelihood of reporting a low summary score. In a similar fashion, a previous study at our institution examining HCAHPS domain scores and key drivers of patient experience with hospital experience across multiple surgical specialties found the HCAHPS summary scores to be lower in noncancer patients. ${ }^{28}$

Information on care transition and communication with the provider team on medications has consistently been shown in available literature to be highly associated with the global rating score. Although often underestimated and overseen, communication with patients on their expectations, medication information, and discharge location is elemental to care delivery. An interesting study by Kliot and colleagues ${ }^{17}$ investigated the effect of patient education bundle on HCAHPS scores. Postintervention, approximately $78 \%$ of patients reported that the physician always explained information in a way that was easy to understand (compared with $74.6 \%$ preintervention). More importantly, all patients thought that the education bundle should be continued. Therefore, even in the modern era of overwhelming technology, patient education strategies remain the cornerstone of establishing a good rapport with the patient and have a positive impact on physician performance scores and hospital ratings. Interestingly, our observed differences were no longer significant in the subgroup analysis, thereby highlighting the importance of a holistic approach for addressing a patient's symptoms and the underlying pathology. Given that there is evidence suggesting a positive correlation between surgeon case volume and patient 

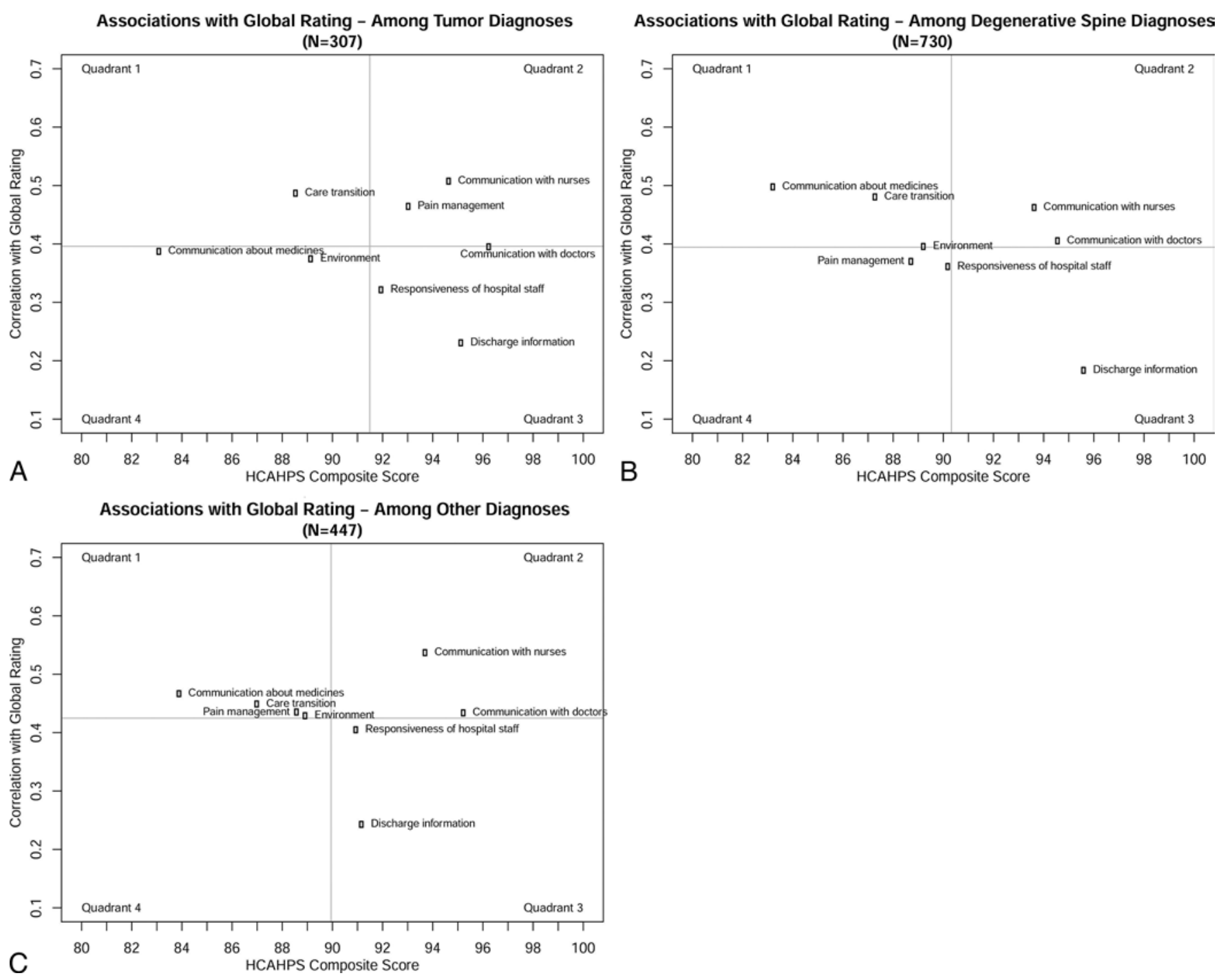

FIG. 2. Key driver analysis demonstrating the association between individual composite measures and global rating. The items falling into the first quadrant should be a first priority. These items have lower than average satisfaction levels while having higher than average correlation with the survey question listed on the $y$-axis. Items falling in quadrant 1 (top priority) are as follows: for patients with brain or spinal tumor $(A, n=307)$, care transition; degenerative spine disease $(B, n=730)$, communication about medicine, care transition, and environment; and other neurosurgical diagnoses $(C, n=447)$, communication about medicines, care transition, pain management, and environment.

satisfaction, provider specialization needs to be examined in future studies investigating factors influencing patient experience with hospital care. ${ }^{30}$ Regarding discharge information, Bull et al. ${ }^{4}$ conducted a study in 2 large community hospitals in Maryland using the Modified Client Satisfaction Questionnaire, which consists of 8 items that measure satisfaction with discharge planning. The authors found that care continuity and the extent to which patients and their family felt prepared to manage care following hospitalization were the most predictive of patient's and family caregiver's satisfaction with discharge information.

Pain management is another important aspect of patient care. Buvanendran and colleagues reported that the prevalence of severe and extreme postoperative pain in patients before and after discharge was 12\%-13\%. They showed that over the first 2 weeks following discharge, $13 \%$ and
$46 \%$ of 441 patients had severe to extreme and moderate to extreme pain, respectively. Furthermore, there was a negative association between pain scores and patient satisfaction with pain medication, concluding that increased pain intensity is correlated with lower patient satisfaction. In addition, Titsworth et al. performed a 10-month, prospective, interrupted time-series trial of a quality improvement project investigating the effect of a standardized postoperative analgesia protocol in neurosurgical patients. ${ }^{29}$ The authors found that their protocol significantly reduced postoperative pain among neurosurgical patients (preintervention $72.1 \%$ vs $82.0 \%$ postintervention) while increasing safety. ${ }^{29}$

Key driver analysis is an effective tool to highlight the patient experience aspects that are most closely correlated with global hospital rating and to determine high-priority 
targets for quality improvement and prudent allocation of resources. Therefore, leveraging these results can facilitate the efforts of surgeons, nurses, and administrators to engage in quality improvement initiatives aimed at specific HCAHPS measures; such efforts will improve patient experience and enhance the summary star score. Overall, we found care transition and communication about medicines, which had low median scores, to be highly associated with a patient's global rating of the institution.

\section{Study Limitations}

Our study is bound by several limitations incumbent to its survey design; as a result, there is a risk of recall as well as nonresponse bias. Unfortunately, we only had access to the date that the survey was returned and not the actual questionnaire completion date. As such, we could not investigate the association between the time to return the questionnaire and scoring. Nevertheless, our study analyzed the CMS-reported data, thereby reflective of our real-world experience; as such, recall and nonresponse bias might be the objective of a future investigation. Furthermore, the single-institution nature of the study poses limitations to the extrapolation of our conclusions to other hospital centers and surgical specialties. Future research should also focus on psychological factors that could impact experience with hospital care, particularly depression, which is known to be prevalent among patients with CNS tumors or degenerative spine disease and to affect the clinical and surgical

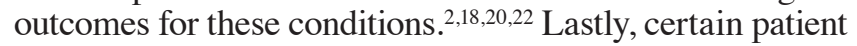
profiles that are more likely to be less satisfied with their inpatient hospital care, including age, sex, and baseline severity of illness, should be examined as well. ${ }^{7}$

\section{Conclusions}

Institutional HCAHPS data can be used to identify domains for which quality of care may be improved, both overall and in specific patient populations. We combined HCAHPS scores with institutional data to investigate differences in perceived experience of hospital care of patients undergoing cranial or spinal operations. We found that patients with a primary diagnosis of brain or spinal tumor compared with those with degenerative spinal disease and those with other neurosurgical diagnoses provided high HCAHPS scores more often in the domains of communication with doctors, pain management, and global rating. Furthermore, spinal patients were less likely to report excellent health despite higher discharge scores. Lastly, key driver analysis revealed care transition and communication about medicines to be potential targets of institutional quality improvement initiatives for patients undergoing inpatient elective cranial and spinal procedures.

\section{Acknowledgments}

This study was supported by funding from the Mayo Clinic Robert D. and Patricia E. Kern Center for the Science of Health Care Delivery.

\section{References}

1. Anhang Price R, Elliott MN, Zaslavsky AM, Hays RD, Leh- rman WG, Rybowski L, et al: Examining the role of patient experience surveys in measuring health care quality. Med Care Res Rev 71:522-554, 2014

2. Arpino L, Iavarone A, Parlato C, Moraci A: Prognostic role of depression after lumbar disc surgery. Neurol Sci 25:145147,2004

3. Boulding W, Glickman SW, Manary MP, Schulman KA, Staelin R: Relationship between patient satisfaction with inpatient care and hospital readmission within 30 days. Am J Manag Care 17:41-48, 2011

4. Bull MJ, Hansen HE, Gross CR: Predictors of elder and family caregiver satisfaction with discharge planning. J Cardiovasc Nurs 14:76-87, 2000

5. Buvanendran A, Fiala J, Patel KA, Golden AD, Moric M, Kroin JS: the incidence and severity of postoperative pain following inpatient surgery. Pain Med 16:2277-2283, 2015

6. Chapman KB: Improving communication among nurses, patients, and physicians. Am J Nurs 109 (11 Suppl):21-25, 2009

7. Danforth RM, Pitt HA, Flanagan ME, Brewster BD, Brand EW, Frankel RM: Surgical inpatient satisfaction: what are the real drivers? Surgery 156:328-335, 2014

8. Darby C, Hays RD, Kletke P: Development and evaluation of the CAHPS hospital survey. Health Serv Res 40:1973-1976, 2005

9. Elliott MN, Beckett MK, Lehrman WG, Cleary P, Cohea $\mathrm{CW}$, Giordano LA, et al: Understanding the role played by Medicare's patient experience points system in hospital reimbursement. Health Aff (Millwood) 35:1673-1680, 2016

10. Fenton JJ, Jerant AF, Bertakis KD, Franks P: The cost of satisfaction: a national study of patient satisfaction, health care utilization, expenditures, and mortality. Arch Intern Med 172:405-411, 2012

11. Giordano LA, Elliott MN, Goldstein E, Lehrman WG, Spencer PA: Development, implementation, and public reporting of the HCAHPS survey. Med Care Res Rev 67:27-37, 2010

12. Goldstein E, Farquhar M, Crofton C, Darby C, Garfinkel S: Measuring hospital care from the patients' perspective: an overview of the CAHPS Hospital Survey development process. Health Serv Res 40:1977-1995, 2005

13. Isaac T, Zaslavsky AM, Cleary PD, Landon BE: The relationship between patients' perception of care and measures of hospital quality and safety. Health Serv Res 45:1024-1040, 2010

14. Jabłońska R, Ślusarz R, Królikowska A, Haor B, Antczak A, Szewczyk M: Depression, social factors, and pain perception before and after surgery for lumbar and cervical degenerative vertebral disc disease. J Pain Res 10:89-99, 2017

15. Jha AK, Orav EJ, Zheng J, Epstein AM: Patients' perception of hospital care in the United States. N Engl J Med 359:1921-1931, 2008

16. Kennedy GD, Tevis SE, Kent KC: Is there a relationship between patient satisfaction and favorable outcomes? Ann Surg 260:592-600, 2014

17. Kliot T, Zygourakis CC, Imershein S, Lau C, Kliot M: The impact of a patient education bundle on neurosurgery patient satisfaction. Surg Neurol Int 6 (Suppl 22):S567-S572, 2015

18. Larson CO, Nelson EC, Gustafson D, Batalden PB: The relationship between meeting patients' information needs and their satisfaction with hospital care and general health status outcomes. Int J Qual Health Care 8:447-456, 1996

19. Lyu H, Wick EC, Housman M, Freischlag JA, Makary MA: Patient satisfaction as a possible indicator of quality surgical care. JAMA Surg 148:362-367, 2013

20. Madhusoodanan S, Ting MB, Farah T, Ugur U: Psychiatric aspects of brain tumors: a review. World J Psychiatry 5:273-285, 2015

21. Maher DP, Wong W, Woo P, Padilla C, Zhang X, Shamloo $B$, et al: Perioperative factors associated with HCAHPS 
responses of 2,758 surgical patients. Pain Med 16:791-801, 2015

22. Pringle AM, Taylor R, Whittle IR: Anxiety and depression in patients with an intracranial neoplasm before and after tumour surgery. Br J Neurosurg 13:46-51, 1999

23. Sacks GD, Lawson EH, Dawes AJ, Russell MM, MaggardGibbons M, Zingmond DS, et al: Relationship between hospital performance on a patient satisfaction survey and surgical quality. JAMA Surg 150:858-864, 2015

24. Schmocker RK, Holden SE, Vang X, Leverson GE, Cherney Stafford LM, Winslow ER: Association of patient-reported readiness for discharge and hospital consumer assessment of health care providers and systems patient satisfaction scores: a retrospective analysis. J Am Coll Surg 221:1073-1082, 1082.e1-1082.e3, 2015

25. Shortell SM, Kaluzny AD: Health Care Management: Organization, Design, and Behavior. Boston: Cengage Learning, 2000

26. Simons Y, Caprio T, Furiasse N, Kriss M, Williams MV, O'Leary KJ: The impact of facecards on patients' knowledge, satisfaction, trust, and agreement with hospital physicians: a pilot study. J Hosp Med 9:137-141, 2014

27. Thiels CA, Hanson KT, Yost KJ, Mathis KL, Cima RR, Zielinski MD, et al: Achieving a 5-star rating: analysis of Hospital Consumer Assessment of Healthcare Providers and Systems (HCAHPS) scores among patients undergoing elective colorectal operations. Surgery 160:902-914, 2016

28. Thiels CA, Hanson KT, Yost KJ, Zielinski MD, Habermann EB, Cima RR: Effect of hospital case mix on the hospital consumer assessment of healthcare providers and systems star scores: are all stars the same? Ann Surg 264:666-673, 2016

29. Titsworth WL, Abram J, Guin P, Herman MA, West J, Davis $\mathrm{NW}$, et al: A prospective time-series quality improvement trial of a standardized analgesia protocol to reduce postoperative pain among neurosurgery patients. J Neurosurg 125:1523-1532, 2016
30. Waljee JF, Hawley S, Alderman AK, Morrow M, Katz SJ: Patient satisfaction with treatment of breast cancer: does surgeon specialization matter? J Clin Oncol 25:3694-3698, 2007

\section{Disclosures}

The authors report no conflict of interest concerning the materials or methods used in this study or the findings specified in this paper.

\section{Author Contributions}

Conception and design: Bydon, Kerezoudis, Alvi, Ubl, Hanson. Acquisition of data: Bydon, Kerezoudis, Alvi, Ubl, Hanson. Analysis and interpretation of data: Bydon, Kerezoudis, Alvi, Ubl, Hanson. Drafting the article: Bydon, Kerezoudis, Alvi, Meyer, Spinner, Habermann. Critically revising the article: Kerezoudis, Alvi, Krauss, Meyer, Spinner, Habermann. Reviewed submitted version of manuscript: Bydon, Kerezoudis, Ubl, Hanson, Krauss, Meyer, Spinner, Habermann. Approved the final version of the manuscript on behalf of all authors: Bydon. Statistical analysis: Kerezoudis, Ubl, Hanson. Study supervision: Meyer, Spinner, Habermann.

\section{Supplemental Information \\ Online-Only Content}

Supplemental material is available with the online version of the article.

Supplemental Tables 1-4. https://thejns.org/doi/suppl/10.3171/ 2017.7.JNS17991.

\section{Correspondence}

Mohamad Bydon: Mayo Clinic, Rochester, MN. bydon.mohamad @mayo.edu. 